\section{Contribution to the Selection of Blackberry Through Fruit Physical Variables}

\author{
Job Teixeira de Oliveira \\ Department of Agronomy, Universidade Federal do Mato Grosso do Sul, \\ Campus CPCS, Chapadão do Sul-MS, Brazil
}

Rubens Alves de Oliveira

Department of Agricultural Engineering, Universidade Federal de Viçosa, Viçosa-MG, Brazil

Priscilla Andrade Silva

Department of Agronomy, Universidade Federal Rural da Amazônia, Campus de Parauapebas, Parauapebas, Pará, Brazil

\section{Paulo Eduardo Teodoro \\ Department of Agronomy, Universidade Federal do Mato Grosso do Sul, Campus CPCS, Chapadão do Sul-MS, Brazil}

Additional index words. fruitful, path analysis, Rosaceae, Rubus

Abstract. To contribute to commercial classification, this work sought to evaluate correlations between fruit mass and other physical characteristics of blackberry fruit, indicating direct and indirect effects of morphology and physical characteristics on blackberry fruit mass. The variables evaluated were the total mass of the blackberry fruit along with its physical components: fruit length, greater transverse diameter, smaller transverse diameter, fruit area, fruit perimeter, and fruit volume. Results of our analyses show that an increase in fruit length, fruit perimeter, and fruit volume reflects an increase in the total mass of the blackberry fruit. Indirectly, greater values of fruit length, greater transverse diameter, and smaller transverse diameter reflect an increase in the perimeter and volume of the blackberry fruit, thus contributing to larger, more attractive fruit.

Black mulberry (Rubus spp.) produces aggregate fruit that are black with an acidic to sweet-acid9c flavor. It is considered a fast return crop, considering that it starts production during the second year of cultivation. Another interesting feature is the possibility of commercialization, because it is a fruit that contributes to a wide variety of products, such as yogurts, jellies, sweets and juices, in addition to being sold in natura and in the form of pulp. (Antunes et al., 2014).

The main objective in marketing blackberries is to develop fruit of greater mass with a large volume, which is consequently more attractive. In this regard, special attention has been given to yielding heavier fruit as the most important agronomic characteristic. Fruit yield is a complex quantity and a characteristic affected by several physical factors. Knowledge of the interrelationships between crop yields contributes to components that improve

Received for publication 9 Apr. 2021. Accepted for publication 10 May 2021.

Published online 22 July 2021.

This project was funded by Fundação Arthur Bernardes.

J.T.O. is the corresponding author. E-mail: job.oliveira@hotmail.com.

This is an open access article distributed under the CC BY-NC-ND license (https://creativecommons. org/licenses/by-nc-nd/4.0/). and to evaluate correlations between mass and other physical characteristics of blackberry fruit, indicating the direct and indirect effects of morphology and physical characteristics on blackberry fruit mass.

\section{Materials and Methods}

The study was conducted in Bicas, Minas Gerais, Brazil, close to the geographic coordinates: $21^{\circ} 43^{\prime} 31.05^{\prime \prime} \mathrm{S}$; $43^{\circ} 3^{\prime} 30.25^{\prime \prime} \mathrm{W}$.

The mulberry fruit, of the Cherokee cultivar, were harvested on 18 Aug. 2020, resulting in a total cultivation cycle of 365 d. The fruit were harvested manually to avoid any type of influence or physical damage, following the recommendation of Santos et al. (1997), which establishes that the fruit must be homogeneous both in maturity and in quality, classifying them by size, shape, and color, and also should not be harvested when moist or supermature. After harvesting, 100 random fruit were selected, with the aim of excluding all those that presented defects, to avoid any type of undesirable influence that could hinder or interfere with the results of the research.

The physical attributes evaluated were the total mass of the blackberry fruit (MA) (measured in grams using a precision scale of 0.1 g) and fruit length (LE), the greater transverse diameter (GD), and the smaller transverse diameter (SD) (measured in millimeters using a $0.01-\mathrm{mm}$ precision digital caliper). In Fig. 1 , photographs illustrating the measurements are presented.

Fruit images were obtained with the aid of a support tripod for a camera, which was based on a platform where the fruit were supported. The photographs were transferred to AutoCAD 2018 (free version) to determine fruit area (expressed in square millimeters) and fruit perimeter (expressed in millimeters).

Fruit volume (VO) was calculated using Eq. [1], according to the methodology of Araujo et al. (2015), as

$$
\mathrm{VO}=\pi \frac{(L E)(G D)(S D)}{6}
$$
stand how the physical variables of fruit affect mass. We report the results of a study that aimed to contribute to the selection of
A

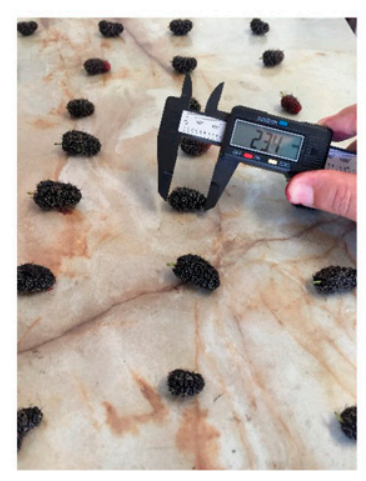

Fig. 1. Blackberry (A) measure of the fruit length, (B) harvested fruit, and $(\mathbf{C})$ measure of the greater transverse diameter.
B
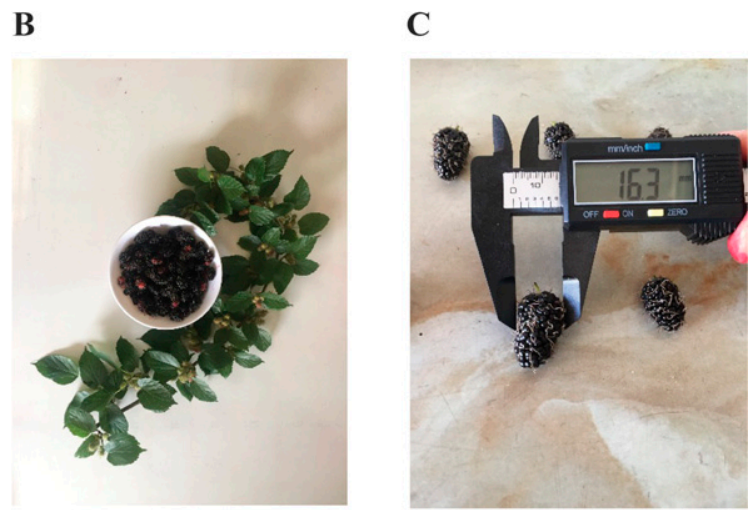

C

1003 

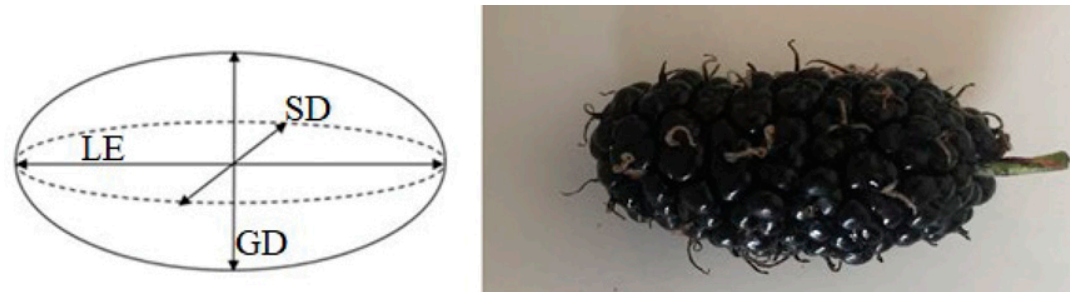

Fig. 2. Schematic representation of the triaxial axes of the blackberry fruit. Source: Adapted from Araujo et al. (2015).

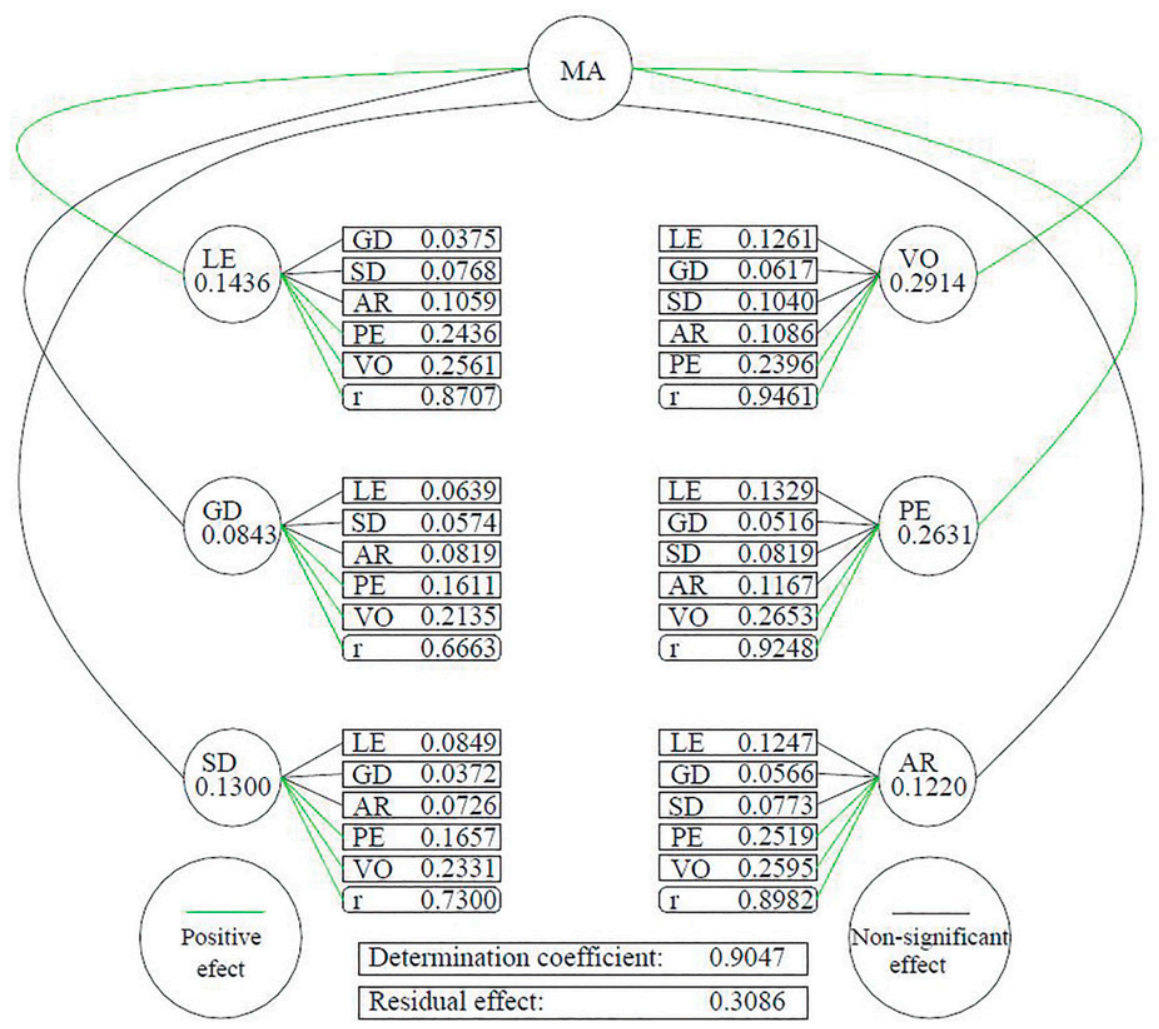

Fig. 3. Path analysis between total mass of the blackberry fruit (MA) with its physical componentsfruit length (LE), greater transverse diameter (GD), smaller transverse diameter (SD), fruit area (AR), fruit perimeter (PE), and fruit volume (VO) — and the path analysis performed.

A path analysis was performed following the methodology described by Cruz (2013), who stated that ignoring the effects of multicollinearity can cause the wrong results. For this, multicollinearity diagnoses must be made to make certain studies feasible. In this sense, the degree of multicollinearity established based on its condition number $(\mathrm{CN})$, which is the ratio between the highest and lowest eigenvalue of the matrix (Montgomery et al., 2012). If $\mathrm{CN}>$ 1000 , multicollinearity is considered severe; if $100 \leq \mathrm{CN} \leq 1000$, multicollinearity is considered moderate to strong; and if $\mathrm{CN}<100$, multicollinearity is considered weak and it is not a problem for the analysis. All statistical analyses were performed using GENES software (Cruz, 2013)

\section{Results and Discussion}

According to the $\mathrm{CN}$ criterion presented by Montgomery et al. (2012), we obtained a
Pearson correlation estimation matrix that indicated moderate to strong multicollinearity $(\mathrm{CN}=675)$. Therefore, a crest trial analysis was performed to correct for multicollinearity.

Our results (Fig. 3) show the variables that had the greatest direct effect on MA. They included LE, PE, and VO, with correlation values of $0.1436,0.2631$, and 0.2914 , respectively. Considering that a variable is viable for direct selection of larger and more attractive fruit, it is necessary that it has a direct effect and a high correlation in the same direction as the main variable. Thus, the variables $\mathrm{LE}, \mathrm{PE}$, and $\mathrm{VO}$ are the most suitable for direct selection, because they have a cause-and-effect relationship with MA. Nonthakod et al. (2019) also found a strong direct effect between MA and LE of blackberry fruit in their path analysis.

This result also indirectly suggests that the perimeter and volume are strongly influenced by the other physical attributes studied. In our study, these results were positive and demonstrate that greater values for $\mathrm{LE}, \mathrm{GD}$, and $\mathrm{SD}$ can be obtained through the indirect selection of those with the greatest fruit volume. Curi et al. (2015) highlighted that small fruit are more suitable for processing, such as in the manufacture of jams and sweets. Larger and more voluminous fruit are more suitable for commercialization in natura.

There was a positive correlation between $\mathrm{PE}$ and the variables LE, MA, area, and VO of the fruit. Nonthakod et al. (2019) found a significant and positive correlation between the width of the blackberry fruit with the length and mass of the fruit, and also found that the weight of the fruit correlated positively with the length and width of the fruit. Their results are similar to those found in our study.

\section{Conclusion}

Via path analysis, it was possible to verify directly that, among the physical components of the study, increasing LE, PE, and VO reflected an increase in MA. Indirectly, greater values of $\mathrm{LE}, \mathrm{GD}$, and SD reflect an increase in the PE and VO of the blackberry fruit, thus contributing to larger, more attractive fruit.

\section{Literature Cited}

Antunes, L.E.C., I.D.S. Pereira, L. Picolotto, G.K. Vignolo, and M.A. Gonçalves. 2014. Produção de amoreira-preta no Brasil. Rev. Bras. Frutic. 36(1):100-111, doi: https://doi. org/10.1590/0100-2945-450/13.

Araujo, W.D., A.L.D. Goneli, R.C. Orlando, E.A.S Martins, and C.P. Hartmann Filho. 2015. Propriedades físicas dos frutos de amendoim durante a secagem. Caatinga Mossoró 28(4):170-180, doi: https://doi.org/10.1590/1983-21252015v28n419rc.

Belay, N. 2018. Genetic variability, heritability, correlation and path coefficient analysis for grain yield and yield component in maize (Zea mays L.) hybrids. Adv. Crop Sci. Technol. 6:399, doi: https://doi.org/10.13057/biodiv/d190445.

Cruz, C.D. 2013. Genes: A software package for analysis in experimental statistics and quantitative genetics. Acta Sci. Agron. 35:271-276, doi: https://doi.org/10.4025/actasciagron.v35i3.21251.

Curi, P.N., R. Pio, P.H.A. Moura, M.H. Tadeu, P.V Nogueira, and M. Pasqual. 2015. Produção de amora-preta e amora-vermelha em Lavras-MG. Cienc. Rural 45(8):1368-1374, doi: https://doi. org/10.1590/0103-8478cr20131572.

Montgomery, D.C., E.A. Peck, and G.G. Vining. 2012. Introduction to linear regression analysis. 5th ed. Wiley, New York, NY.

Nonthakod, S., P. Wiwacharn, C. Sangsiri, and T. Kajonphol. 2019. Correlation and path coefficient for economic traits of fruit mulberry (Morus spp.) based on criteria mulberry selection. Appl. Mech. Mater. 891:66-70, doi: https://doi.org/10.4028/www. scientific.net/AMM.891.66

Santos, A.M., M.C. Bassols, and J.C.M Madait. 1997. A cultura da amora-preta I: Empresa Brasileira de Pesquisa Agropecuária, Centro ele Pesquisa Agropecuátio de Clima Temperado. 2nd rev. ed. Embrapa·SPI, Pelotas, Brazil. 